\title{
CIÊNCIA E LINGUAGEM: INTEGRANDO DISCURSO E CONTEXTO NA ANÁLISE DAS CONCLUSÕES DE ARTIGOS CIENTÍFICOS EXPERIMENTAIS DO MEMÓRIAS DO INSTITUTO OSWALDO CRUZ (1909-1919 E 1980-1989)
}

\author{
Bianca Walsh* \\ Universidade do Estado do Rio de Janeiro \\ Rio de Janeiro, RJ, Brasil
}

\begin{abstract}
Resumo: Neste trabalho, foram analisadas as conclusões dos artigos científicos experimentais de um periódico brasileiro tradicional, considerando os períodos de 1909. 19 e 1980-89. A análise integrou língua e contexto ao revelar tipos de argumentos, movimentos retóricos e traços linguísticos. Os achados foram a mudança de um discurso linear e menos retoricamente elaborado no primeiro período para uma densidade e ciclicidade altamente retóricas no segundo. Esses achados correlacionam-se com a mudança de uma comunidade de prestígio, coesa e pequena para uma comunidade grande e pressionada a adaptar-se aos parâmetros da big science sem nenhum apoio governamental. São discutidas contribuições aos estudos de gênero, estudos da ciência e ensino para fins acadêmicos.
\end{abstract}

Palavras-chave: Ciência e linguagem. Artigo científico experimental. Seção de conclusão. Estudos de gêneros.

1 INTRODUÇÃO

Os estudos de gênero têm sido tradicionalmente associados com fins pedagógicos. A motivação para isso é a crença (compartilhada pela maioria dos estudiosos dessa área) de que o domínio da compreensão e da produção de gêneros específicos garantiria um acesso mais suave para grupos sociais específicos. Um plano de formação/educação que considere gêneros é, então, estratégico para "o sucesso do aprendiz em todas as situações retóricas" (JOHNS et al., 2006, p. 248). Dessa forma, para empoderar aprendizes e democratizar sua participação social, é interessante que desenvolvam uma metaconsciência dos aspectos dos gêneros (RAMANATHAN; KAPLAN, 2000).

Para além da aplicação pedagógica, alguns autores têm estudado gêneros para retratar comunidades científicas, considerando suas práticas sociais, crenças e objetivos específicos (SALAGER-MEYER, 1999; PEACOCK, 2002; SAMRAJ, 2002; AYERS, 2008; BRUCE, 2008). Em geral, estes estudos analisam comunidades de disciplinas diferentes ou de diferentes áreas do conhecimento (e.g. ciências sociais vs ciências físicas).

\footnotetext{
*Doutora em Letras. Email: bcnwalsh@gmail.com.
} 
Para ambas as aplicações, um modelo de gênero que consiga abrangência e flexibilidade ao mesmo tempo é um ganho valoroso. Em termos pedagógicos, ele forneceria a professores/formadores a oportunidade de simular competentemente a realidade discursiva que os aprendizes experimentarão no futuro. Em estudos sobre comunidades de discurso, o modelo favoreceria análises mais críticas e mais profundas - triangulando diferentes perspectivas sem perder de vista os aspectos que promovem mudanças em hábitos de discurso.

Com frequência, no entanto, os estudos de gênero consideram poucos elementos do discurso e geralmente os abordam com enfoque desigual: alguns pesquisadores dão mais atenção aos aspectos linguísticos, outros destacam a estrutura retórica. Para ilustrar como esta prática pode levar a equívocos, Coracini (1990) demonstrou que considerar apenas aspectos linguísticos nos artigos de pesquisa leva à conclusão ingênua de que o discurso científico é essencialmente objetivo. Na verdade, a impressão de objetividade é por si mesma um recurso argumentativo, sustentando a "ilusão de evidência empírica".

Alguns autores já argumentaram a favor de uma análise integradora. Swales (1990, 2004) usou evidências linguísticas como apoio para a caracterização de movimentos retóricos. Atkinson (1999) foi particularmente feliz ao cruzar a análise linguística, a análise retórica e a análise do contexto histórico em seu estudo. Bruce (2008) argumentou a favor da inclusão dos tipos de conhecimento processual (o que chamou "gêneros cognitivos") na análise. No entanto, a sistematização de um modelo integrador para a análise de gêneros ainda é um desafio.

O objetivo deste artigo é responder a este desafio ao propor um modelo integrador, considerando especificamente as conclusões dos artigos científicos experimentais. O modelo fundamenta-se na Teoria dos Atos de Fala, considerando sua aplicação estendida ao discurso ("a macroestrutura pragmática", van Dijk, 1977). Além disso, é inspirado na prática de análise do discurso de Atkinson, que adota dois procedimentos descritivos complementares: "a leitura analítica dos textos como imbuídos profundamente de seus contextos sócio-históricos [...] e a "leitura a partir de", desses contextos a partir dos textos em si" (1999, p. 60).

\section{ESTUDO}

O objeto deste estudo é uma coleção de artigos científicos experimentais de um periódico brasileiro renomado, "Memórias do Instituto Oswaldo Cruz" (MIOC), em dois momentos diferentes, 1909-1919 e 1980-1989. Esse é o periódico mais velho no Brasil, publicando ainda hoje, da área de Ciências da Vida.

\subsection{O PERIÓDICO E OS PERÍODOS DE TEMPO ESCOLHIDOS}

O MIOC é um veículo relevante para a produção científica no Brasil desde que começou (1909). Em seus primórdios, registrou a chegada do novo e revolucionário paradigma microbiológico, trazido por Oswaldo Cruz da França. Nos dias atuais, o periódico é reconhecido internacionalmente por sua excelência. 
Os dois períodos escolhidos, 1909-1919 e 1980-1989, representam momentos chave na história, praticamente opostos em termos de oportunidade para os cientistas (SCHWARTZMAN, 1991 e 1982). O primeiro é caracterizado como a fase da ilustração brasileira, um momento favorável para os cientistas do Brasil que foram reconhecidos internacionalmente. O outro período é caracterizado como uma época de crise, marcada pela falta de financiamento e apoio e pela rápida internacionalização da ciência. Os cientistas neste momento são considerados "grupo de pressão" (SCHWARTZMAN, 1991 e 1994), já que tinham que lutar por recursos e por um lugar no cenário da big science.

\subsection{SELEÇÃO DO CORPUS}

O corpus preliminar incluiu cinco amostras de conclusões para cada um dos períodos. A análise preliminar ajudou a determinar a extensão de um padrão discursivo (NWOGU, 1997, p. 121) e funcionou como treinamento para a análise definitiva. Essa análise foi submetida ao critério de validação de concordância intra-avaliador (PEACOCK, 2002, p. 485) seis meses após a primeira análise.

O corpus definitivo incluiu 12 conclusões de cada período, selecionadas aleatoriamente. A análise definitiva foi submetida a dois critérios de validação: concordância intra-avaliador, quatro meses após a primeira análise, e concordância interavaliador. Uma estudante de Doutorado em Linguística, cuja tese incluiu a análise de movimentos retóricos, avaliou $25 \%$ do corpus. Particularmente, a concordância interavaliador foi realizada apenas para a análise de movimentos retóricos, já que a análise dos tipos de argumentos é a novidade proposta neste trabalho e exigiria longo treinamento de outros avaliadores. As taxas de concordância foram 92,79\% (intra) e $89,61 \%$ (inter). Um alto grau de concordância sugere que a interpretação tem uma "realidade psicológica" (KANOKSILAPATHAM, 2005, p. 273).

\subsection{PROCEDIMENTOS DE ANÁLISE}

A análise incluiu dois procedimentos complementares: a leitura dos textos após o estudo de dados históricos e sociais (leitura contextual) e a leitura dos textos como indicadores simbólicos dos aspectos sociais e históricos (leitura interpretativa).

Para a leitura contextual, o contexto histórico geral de ambos os períodos foi estudado, considerando aspectos locais relativos ao periódico e a sua comunidade discursiva. As fontes de dados foram textos de historiadores e textos publicados no MIOC, tais como editoriais e notas de homenagem. A organização desses dados seguiu os critérios propostos por Swales (1990, p. 24-27) para caracterizar comunidades discursivas: objetivos públicos, mecanismos de intercomunicação, gêneros compartilhados e posição epistemológica compartilhada. $\mathrm{O}$ único critério que não foi considerado foi o léxico especializado, que exigiria mais tempo de pesquisa. 
Para a leitura interpretativa, a análise ocorreu em três fases: 1) verificação da presença de argumentação; 2) avaliação dos movimentos retóricos; 3) avaliação dos tipos de argumentos e da estrutura argumentativa.

Além disso, os aspectos linguísticos foram submetidos a uma análise computadorizada, ajudando a evidenciar as leituras contextuais e interpretativas. Para Upton e Connor (2001, p. 318), a análise em múltiplos níveis, combinando a análise dos movimentos retóricos manualmente categorizados e a análise computadorizada dos aspectos léxico-gramaticais, é eficaz e valorosa.

De forma geral, o modelo de análise integrou os três níveis de linguagem, locucional, ilocucional e perlocucional, correspondentes, respectivamente, aos aspectos linguísticos, movimentos retóricos e tipos de argumentos. Esses três níveis de linguagem combinados foram confrontados com os dados contextuais. A Figura 1 demonstra a relação intrincada desses elementos.

\section{Figura 1 - Modelo de análise}

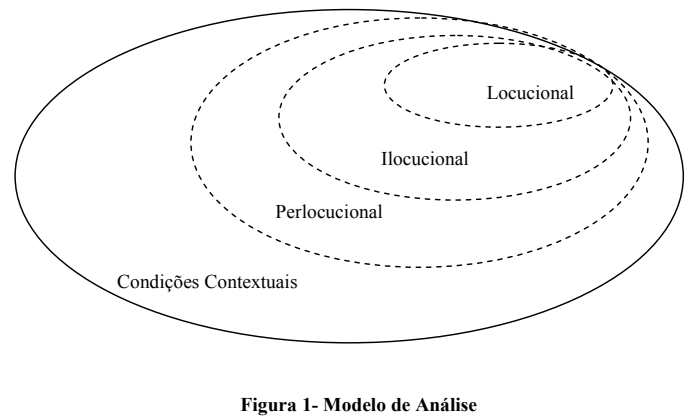

Observando a imagem cuidadosamente, é possível ver através dela partindo das condições contextuais para o nível locucionário e vice-versa. Essa representação enfatiza o fato de que, quando fenômenos discursivos são considerados, não há nenhum ponto privilegiado para o início da análise.

\subsubsection{ANÁLISE DOS ASPECTOS LINGUÍSTICOS (NÍVEL LOCUCIONAL)}

Para a análise dos aspectos linguísticos, o corpus foi examinado pelas ferramentas Wordlist e Concordance do Wordsmith tools 5.0. O concordanciador foi usado especificamente para buscas refinadas, tais como a de advérbios, filtrando-se a busca com terminações típicas de advérbios. A outra ferramenta forneceu informações sobre palavras específicas ou tipos de palavra, tal como o verbo modal "pode". O programa fornece informações sobre a frequência dos itens e a distribuição dos itens no corpus.

A escolha dos itens foi guiada principalmente pela busca de marcas de argumentação e subjetividade. A busca foi inspirada em estudos sobre a relação entre a modalização e a argumentação (KOCH, 2006; GUIMARÃES, 2001; NEVES, 2007); as hipóteses levantadas com o uso do programa Unitex; e hipóteses originadas da autora sobre o discurso científico. 
Tabela 1 - Elementos e categorias linguísticas

\begin{tabular}{|c|c|}
\hline Elementos/categorias & Resultados da busca \\
\hline Verbo ser & é; são; era; eram \\
\hline Verbos modais & poder e dever (em diferentes flexões) \\
\hline Advérbios em mente & $\begin{array}{l}\text { possivelmente; perfeitamente; principalmente; provavelmente; facilmente; } \\
\text { absolutamente; realmente; parcialmente; extremamente; determinadamente; } \\
\text { meticulosamente; detalhadamente; frequentemente; geralmente; dificilmente; } \\
\text { somente; totalmente; normalmente; substancialmente; visivelmente; } \\
\text { potencialmente; profundamente; essencialmente; preferivelmente; } \\
\text { relativamente; corretamente; enormemente; favoravelmente; fortemente; } \\
\text { extraordinariamente; classicamente; claramente; aparentemente; } \\
\text { predominantemente; notoriamente }\end{array}$ \\
\hline Uso da $1^{\mathrm{a}}$ pessoa e da voz passiva & verbos na $1^{\mathrm{a}}$ pessoa do plural; o pronome 'nós'; voz passiva \\
\hline Modos e tempos verbais & subjuntivo; verbos no futuro do pretérito; verbos no futuro do presente \\
\hline Conectivos de contraste & $\begin{array}{l}\text { mas; entretanto; por outro lado; ao contrário; não obstante; enquanto; ainda; } \\
\text { contudo; embora }\end{array}$ \\
\hline Conectivos de causa e efeito & em vista disso; devido a; assim; por isso; porque; já que \\
\hline $\begin{array}{l}\text { Expressões e conectivos de adição e } \\
\text { ênfase }\end{array}$ & também; mesmo; realmente; da mesma forma; de fato; além disso; incluindo \\
\hline Expressões de intensidade & muito; tudo; poucos; somente; apenas; quase; parcial \\
\hline Adjetivos & possível; necessário; difícil; importante; fácil; provável; correto; conveniente \\
\hline Verbos de cognição & achar; julgar; pensar; concluir; ver (compreender); verificar; saber \\
\hline Verbos de volição & querer, precisar \\
\hline $\begin{array}{l}\text { Verbos que representam a relação do } \\
\text { falante com o objeto de conhecimento }\end{array}$ & $\begin{array}{l}\text { verificar; obter; identificar; observar; parecer; notar; merecer; detectar; } \\
\text { sugerir }\end{array}$ \\
\hline
\end{tabular}

O programa Unitex 2.0 funcionou como o primeiro identificador de algumas classes de palavra, porque ele tem dicionários etiquetados (embora o etiquetador não seja perfeito). Uma falha grande desse programa, entretanto, é o fato de que os textos não podem ser tratados separadamente - o que explica o uso do Wordsmith como o programa definitivo de busca.

\subsubsection{ANÁLISE DE MOVIMENTOS RETÓRICOS (NÍVEL ILOCUCIONAL)}

Para identificar os movimentos retóricos, evidências textuais e linguísticas foram combinadas (PEACOCK, 2002, p. 485). As evidências eram verbos, marcadores discursivos, marcadores metadiscursivos (MORAES, 2005) ou estruturas textuais tais como narrativas (Tabela 2 , mais adiante).

Os movimentos retóricos usados neste trabalho (Tabela 3, mais adiante) foram uma combinação dos movimentos retóricos propostos por Swales (1990) e dos movimentos novos identificados no corpus preliminar.

\subsubsection{ANÁLISE DOS ARGUMENTOS (NÍVEL PERLOCUCIONAL)}

Para verificar a presença de argumentação nas sessões de conclusão, usamos a modalização como um índice geral. A modalização é a manifestação da subjetividade 
do falante e de seu relacionamento com o ouvinte. A conexão entre a modalização e a argumentação parece ocorrer através de três liames. O primeiro deles é o debate, a negociação entre as partes. Por meio da modalização, o locutor marca os "tipos de atos que deseja realizar e fornece ao interlocutor pistas quanto as suas intenções" (KOCH, 2006, p. 86). Neves (2007, p. 200) argumenta que

em um enunciado marcadamente modalizado, também deva estar mais marcada a função interpessoal, exatamente pela evidente presença do falante e do destinatário, tanto no comprometimento epistêmico (que se liga a um papel semântico do tipo experimentador, ligado ao falante) como no envolvimento deôntico (que envolve as diversas pessoas do discurso, centrando-se no ouvinte). (NEVES, 2007, p. 200)

\section{Tabela 2 - Exemplos de movimentos retóricos}

\begin{tabular}{|c|c|c|}
\hline $\begin{array}{l}\text { Evidências } \\
\text { Textuais/linguísticas }\end{array}$ & Exemplos: & Interpretação \\
\hline Verbos & $\begin{array}{l}\text { o parasitismo das glândulas anais pelo } \\
\text { T.cruzi nos gambás sugere um grau elevado } \\
\text { de adaptação hospedeiro-parasita... }\end{array}$ & $\begin{array}{l}\text { O verbo aponta para uma conclusão do fato } \\
\text { anterior, com um grau de incerteza, no } \\
\text { entanto: 'dedução e hipótese'. }\end{array}$ \\
\hline Marcadores Discursivos & $\begin{array}{l}\text {... um grau elevado de adaptação } \\
\text { hospedeiro-parasita, dado que os parasitas } \\
\text { estão protegidos contra à resposta imune no } \\
\text { lúmen das glândulas... }\end{array}$ & $\begin{array}{l}\text { O marcador aponta para uma explicação da } \\
\text { conclusão prévia: 'Explicação'. }\end{array}$ \\
\hline Elementos textuais & $\begin{array}{l}\text { Após o uso contínuo de inseticida com ação } \\
\text { residual, o T. infestans foi erradicado, } \\
\text { interrompendo a transmissão doméstica da } \\
\text { doença de Chagas. O P. megistus, espécie } \\
\text { nativa de grande mobilidade, circulando } \\
\text { ativamente do ambiente silvestre para o } \\
\text { doméstico, passou a ser o único triatomíneo } \\
\text { capturado, cuja colonização domiciliar é } \\
\text { impedida pela pressão do inseticida utilizado } \\
\text { na Vigilância Epidemiológica aí implantada } \\
\text { a partir de } 1974 \text { (Dias, 1982). }\end{array}$ & $\begin{array}{l}\text { Toda a passagem é narrativa, com verbos e } \\
\text { expressões de tempo no passado: "narrativa } \\
\text { do fenômeno". }\end{array}$ \\
\hline Outras evidências & $\begin{array}{l}\frac{\text { Os fatos }}{\text { de transmissão dos }}, \frac{\text { somados }}{\text { "pêrosçam a da doença de }} \\
\text { Chagas... }\end{array}$ & $\begin{array}{l}\text { Neste caso, as palavras sublinhadas } \\
\text { sugerem uma metalinguagem sobre o texto. } \\
\text { O sintagma "os fatos" imprime um caráter } \\
\text { objetivo a tudo que foi previamente dito. } \\
\text { Essa passagem ilustra os "marcadores } \\
\text { ideacionais" (MORAES, 2005, p. } 81 \text { ), isto } \\
\text { é, organizadores de blocos de ideias. O } \\
\text { verbo 'reforçar' contribui para o movimento } \\
\text { geral de dedução. Então, trata-se de um } \\
\text { exemplo de "dedução e hipótese". }\end{array}$ \\
\hline
\end{tabular}

O segundo liame é a dúvida, a incerteza da argumentação, que particularmente favorece o debate. Esse aspecto é manifestado pela distância ou pela proximidade do locutor com relação ao que diz $(\mathrm{KOCH}, 2006$, p. 86). A modalização epistêmica, particularmente, materializa os graus de incerteza em termos do conhecimento e das percepções de mundo do locutor. Este tipo de modalização é encontrado especialmente em discursos técnicos e científicos (NEVES, 2007). 
(1)

Tabela 3 - Movimentos retóricos nas seções de conclusão

\begin{tabular}{|c|c|c|}
\hline Movimentos Retóricos & Referência & Exemplos: \\
\hline $\begin{array}{l}\text { Declaração de } \\
\text { Resultados }\end{array}$ & Swales, 1990 & $\begin{array}{l}\text { Estas granulações têm eletividade para o gram, em relação ao resto do } \\
\text { bacilo. }\left(\mathrm{XB}^{1}\right)\end{array}$ \\
\hline Informação Prévia & Swales, 1990 & $\begin{array}{l}\text { Na utilização da sorologia como rotina para auxílio diagnóstico é } \\
\text { conveniente que as técnicas utilizadas sejam de fácil operacionalização e } \\
\text { interpretação, não envolvendo equipamentos ou reagente de alto custo. } \\
\text { (YG) }\end{array}$ \\
\hline Resultado Inesperado & Swales, 1990 & $\begin{array}{l}\text {... “... não foi possível se notar qualquer diferença significativa entre os } \\
\text { camundongos infectados com cem cercárias da cepa Porto Rico do } S . \\
\text { mansoni e aqueles com igual infecção pela cepa Feira de Santana. (YE) }\end{array}$ \\
\hline $\begin{array}{l}\text { Referência à Pesquisa } \\
\text { Prévia (comparação) }\end{array}$ & Swales, 1990 & $\begin{array}{l}\text { Quay e Levine, 1959, mostraram, com o uso de colchicina em ratos recém- } \\
\text { nascidos, que as células de um determinado lóbulo mantinham-se em iguais } \\
\text { atividades mitóticas e desenvolvimento citológico, mas que esses } \\
\text { parâmetros diferiam dos encontrados em outros lóbulos. (corpus XA) }\end{array}$ \\
\hline $\begin{array}{l}\text { Referência à Pesquisa } \\
\text { Prévia (corroboração) }\end{array}$ & Swales, 1990 & $\begin{array}{l}\text { As passagens sucessivas em camundongos são capazes muitas vezes de } \\
\text { modificar a virulência das cepas de toxoplasma, como tem sido } \\
\text { demonstrado por Coutinho e Mendonça, } 1975 \ldots \text { (YC) }\end{array}$ \\
\hline Explicação & Swales, 1990 & $\begin{array}{l}\text {... visto que, no lúmen das glândulas os mesmos estão protegidos da } \\
\text { resposta imune, podendo daí serem disseminados para os tecidos via } \\
\text { corrente circulatória. (YH) }\end{array}$ \\
\hline Dedução e Hipótese & Swales, 1990 & O estradiol é secretado possivelmente pelas células de Leydig... (YB) \\
\hline Recomendação & Swales, 1990 & $\begin{array}{l}\text { A possibilidade de existência de alterações celulares semelhantes em outras } \\
\text { estruturas do Sistema Nervoso Central, merece ser também examinada a } \\
\text { partir de metodologia semelhante. (YA) }\end{array}$ \\
\hline $\begin{array}{l}\text { Narrativa do } \\
\text { Fenômeno }\end{array}$ & Nosso corpus & $\begin{array}{l}\text { A epidemiologia da doença de Chagas neste município caracteriza-se por } \\
\text { uma primeira fase em que o vetor prevalente era o T. infestans, [...] cuja } \\
\text { colonização domiciliar é impedida pela pressão do inseticida utilizado na } \\
\text { Vigilância Epidemiológica aí implantada a partir de } 1974 \text { (Dias, 1982). } \\
\text { (YH) }\end{array}$ \\
\hline Anúncio de Limitação & Nosso corpus & $\begin{array}{l}\text { A questão está limitada a saber si se póde progredir nesse sentido ou não. } \\
\text { Nosso parecer seria precoce, dado o numero pequeno de experiências... } \\
\text { (XA) }\end{array}$ \\
\hline $\begin{array}{l}\text { Justificativa de } \\
\text { Limitação }\end{array}$ & Nosso corpus & $\begin{array}{l}\text { Não foram porém as pesquizas continuadas, devido à alta temperatura } \\
\text { ambiente que impedia se evitasse a fluidificação da membrana de gelatina } \\
\text { durante a experiência. (XA) }\end{array}$ \\
\hline Retomada de Método & Nosso corpus & $\begin{array}{l}\text { Neste trabalho, utilizaram-se } 4 \text { antígenos de diferentes procedências e } \\
\text { manteve-se constante a técnica de preparo dos antígenos, assim como todas } \\
\text { as etapas de reação. (YC) }\end{array}$ \\
\hline $\begin{array}{l}\text { Anúncio de } \\
\text { Continuidade de } \\
\text { Pesquisa }\end{array}$ & Nosso corpus & $\begin{array}{l}\text { A esse ponto pretendemos ainda voltar quando dispuzermos de maior } \\
\text { material. (XC) }\end{array}$ \\
\hline Implicação Prática & Nosso corpus & $\begin{array}{l}\text { Assim sendo, além da padronização da técnica da reação, do equipamento } \\
\text { óptico e dos reagentes, é necessária também a padronização do antígeno. } \\
\text { (2C) }\end{array}$ \\
\hline Anúncio de Ineditismo & Nosso corpus & $\begin{array}{l}\text { Na peste das galinhas acreditamos serem nossos os primeiros ensaios de } \\
\text { fixação do complemento. (XC) }\end{array}$ \\
\hline $\begin{array}{l}\text { Agradecimento aos } \\
\text { Colaboradores }\end{array}$ & Nosso corpus & $\begin{array}{l}\text { Agora, ao terminar, é o nosso dever testemunhar, ainda uma vez os nossos } \\
\text { mais sinceros agradecimentos aos Snrs. Professores Drs. Domingos de } \\
\text { Góes, Fernando Terra. (XE) }\end{array}$ \\
\hline $\begin{array}{l}\text { Justificativa do } \\
\text { Agradecimento }\end{array}$ & Nosso corpus & $\begin{array}{l}\text {... por terem colocado à nossa inteira disposição os doentes dos seus } \\
\text { serviços, para todos os estudos e pesquizas que quizessemos empreender, } \\
\text { facilitando por todos os modos o nosso trabalho e acompanhando com } \\
\text { maior interesse os nossos resultados. (XE) }\end{array}$ \\
\hline
\end{tabular}

${ }^{1}$ As letras representam os corpora preliminares diferentes. A letra X representa o corpus de 1909-19, Y, o corpus de 1980-89. As demais letras refletem a sequência dos diferentes artigos de cada período.

WALSH, Bianca. Ciência e linguagem: integrando discurso e contexto na análise das conclusões de artigos científicos experimentais do Memórias do Instituto Oswaldo Cruz (1909-1919 e 1980-1989). Linguagem em

(Dis)curso - LemD, Tubarão, SC, v. 15, n. 1, p. 95-115, jan./abr. 2015. 
Finalmente, o terceiro liame diz respeito ao consenso, o objeto da negociação na argumentação, manifestado geralmente por meio de valores. Especificamente, o eixo axiológico inclui valores morais, afetivos e técnicos, assim como os sentimentos e a vontade do locutor $(\mathrm{KOCH}, 2006$, p. 85). Outra forma de expressão acontece por meio da especulação, que antecipa a realidade que o locutor quer ver aceita por seu interlocutor em direção a um acordo. Algumas das marcas da especulação são os tempos e os modos verbais do domínio do imaginário (irrealis).

Portanto, a análise perlocucional foi baseada nessas três noções: dúvida, debate e busca por consenso. As evidências para a dúvida foram "operadores argumentativos" (KOCH, 2006, p. 85) e os outros elementos gerais de modalização tais como verbos, advérbios, adjetivos e substantivos. As evidências para os relacionamentos entre interlocutores foram os tipos de asserção (GUIMARÃES, 2001, p. 70-71), os processos de unipessoalização (NEVES, 2007, p. 167-168) e o uso da primeira pessoa do singular, os modos verbais e a evidencialidade (NEVES, 2007, p. 200). As evidências para a busca do consenso foram juízos de valor expressos por adjetivos, advérbios, substantivos; especulação, expressa por tempos e modos do irrealis; tematização/foco e ênfase (GUIMARÃES, 2001). A Tabela 4 mostra essas evidências com exemplos.

Tabela 4 - Exemplos de evidências linguísticas da argumentação: o caso da modalização

\begin{tabular}{|c|c|c|}
\hline Noções Argumentativas & Evidências Linguísticas & Exemplos \\
\hline \multirow[t]{5}{*}{ Dúvida } & Verbos & $\begin{array}{l}\text {... uma mesma linhagem isogênica pode } \\
\text { apresentar diferentes graus de resistência... } \\
\text { (YF) }\end{array}$ \\
\hline & Operadores Argumentativos & tem sido pouco estudada... (YC) \\
\hline & Substantivos & A possibilidade de existência... (YA) \\
\hline & Advérbios & Possivelmente isto se deve ao fato de que... \\
\hline & Adjetivos em posição predicativa & $\begin{array}{l}\text { É possível também que a intoxicação se } \\
\text { realiza... (XF) }\end{array}$ \\
\hline \multirow[t]{3}{*}{ Debate } & Tipo de asserção & Nenhum exemplo encontrado. \\
\hline & $\begin{array}{l}\text { Unipessoalização ou usos da primeira } \\
\text { pessoa }\end{array}$ & $\begin{array}{l}\text { Com respeito ao nosso ponto da vista, julgamos } \\
\text { que... (YD) }\end{array}$ \\
\hline & Evidencialidade & $\begin{array}{l}\text {... o que está de acordo com os trabalhos de } \\
\text { Chagas (1982).(YG) }\end{array}$ \\
\hline \multirow[t]{3}{*}{ Busca do consenso } & Juízos de Valor & $\begin{array}{l}\text { Nosso aparelho é extraordinariamente barato e } \\
\text { fácil ... (X A) }\end{array}$ \\
\hline & $\begin{array}{l}\text { Especulação (tempos e modos do } \\
\text { irrealis) }\end{array}$ & $\begin{array}{l}\text {... sendo que essas diferenças poderiam ter } \\
\text { relação com possíveis diferenças antigênicas. } \\
\text { (YC) } \\
\text { … caso sejam suspensas as atividades de } \\
\text { vigilância e borrificação exercidas. (YH) }\end{array}$ \\
\hline & Tematização/focalização e ênfase & $\begin{array}{l}\text { Chama a atenção a observação de que uma } \\
\text { mesma linhagem isogênica pode apresentar... } \\
\text { (YF) }\end{array}$ \\
\hline
\end{tabular}

Finalmente, os tipos e a estrutura dos argumentos foram analisados com base no trabalho de Perelman e de Olbrechts-Tyteca (2005). O tipo de estrutura argumentativa encontrado tipicamente foi o da baseada na estrutura do real. Na verdade, a natureza das conclusões, estruturada da informação específica para a geral, representando um movimento de dentro para fora, favorece a predominância da relação de causa e efeito. 


\section{Tabela 5 - Tipos de argumentos}

\begin{tabular}{|c|c|}
\hline Tipo & Exemplo: \\
\hline Pragmático & $\begin{array}{l}\text { As passagens sucessivas em camundongos são } \\
\text { capazes muitas vezes de modificar a virulência das } \\
\text { cepas de toxoplasma, como tem sido demonstrado } \\
\text { por Coutinho \& Mendonça, 1975, sendo que estas } \\
\text { diferenças de comportamento entre cepas poderiam } \\
\text { ter relação com possíveis diferenças antigênicas. } \\
\text { Todos esses dados demonstram que os títulos de } \\
\text { anticorpos séricos para toxoplasmose por } \\
\text { imunofluorescência indireta podem sofrer } \\
\text { variações relacionadas com os antígenos usados. } \\
\text { Assim sendo, além da padronização da técnica da } \\
\text { reação, do equipamento óptico e dos reagentes, é } \\
\text { necessária também a padronização do antígeno. }\end{array}$ \\
\hline
\end{tabular}
(YC)

\section{Análise}

Neste caso, "as diferenças antigênicas" são identificadas como a única causa para a mudança dos resultados nas cepas. Os investigadores parecem fazer isso por meio do movimento de "referência à pesquisa prévia". Mesmo quando citam literatura divergente, corroboram a causa privilegiada com os movimentos de "declaração dos resultados" e "referência à pesquisa prévia por corroboração". Os movimentos de "dedução e hipótese" e "implicação prática" reforçam a relação de causa e efeito privilegiada.

Linguisticamente, a corroboração está materializada no conector "contudo", que expressa o contraste e, sobretudo, um deslocamento do foco, que conduz o leitor a se concentrar na ideia subsequente (isto é, a causa privilegiada).

O movimento de "dedução e hipótese" (introduzido por "Todos esses dados...") continua o texto com uma consolidação aparente da causa destacada.

Desperdício Esta modificação simplifica muito a técnica das injeções e as torna possíveis com recursos muito limitados e que se encontram por toda a parte. (XE)

Os valores da facilidade e da economia no movimento de implicação prática recaem sobre a metodologia (evocada por "modificação"), apoiando o aproveitamento da técnica presente.

\begin{tabular}{|c|c|c|}
\hline Direção & $\begin{array}{l}\text { A comparação entre as figuras apresentadas indica } \\
\text { haver um aumento de destruição de parênquima } \\
\text { celular da gl. pineal, quando se aumentava o } \\
\text { numero de estimulações, sugerindo a existência de } \\
\text { uma relação entre o estímulo sonoro e o } \\
\text { aparecimento de aspectos destrutivos tão intensos } \\
\text { nas gls. pineais destes animais. } \\
\text { A possibilidade de existência de alterações } \\
\text { celulares semelhantes em outras estruturas do } \\
\text { Sistema Nervoso Central, merece ser também } \\
\text { examinada a partir de metodologia semelhante. } \\
\text { (YA) }\end{array}$ & $\begin{array}{l}\text { Há uma ideia de propagação por contágio } \\
\text { subentendida para as outras estruturas do Sistema } \\
\text { Nervoso Central. A ideia é uma propagação do } \\
\text { efeito. O argumento é fundado na ideia de que há } \\
\text { um fluxo natural de propagação, e, por isso, é } \\
\text { necessário continuar a pesquisa. }\end{array}$ \\
\hline Superação & $\begin{array}{l}\text { O isolamento dos parasitos provenientes das } \\
\text { glândulas anais (GA09), só foi possível em meio } \\
\text { NNN. Esta dificuldade pode estar relacionada a } \\
\text { heterogeneidade das amostras de T. cruzi (Brener, } \\
\text { 1977; Milha \& Cibulskis, 1986), que se refletiria } \\
\text { também no comportamento em meio de cultura, já } \\
\text { que Thomaz et al. (1984 e Steindel et al. (1988) } \\
\text { isolaram parasitas de glândulas anais em meio LIT } \\
\text { de gambás experimentalmente e naturalmente } \\
\text { infectadas, respectivamente. No entanto, após o } \\
\text { isolamento dos parasitas das glândulas, nossa cepa } \\
\text { apresentou abundante crescimento em meio LIT. } \\
\text { resultado este também observado quando se } \\
\text { procedia ao isolamento diretamente das formas } \\
\text { sanguíneas via hemocultura ou xenodiagnóstico, } \\
\text { sugerindo poder existir no conteúdo glandular deste } \\
\text { gambá (GA09). } \\
\text { algum fator de inibição de crescimento do parasita. } \\
\text { Este fator de inibição poderia ser anulado no meio } \\
\text { NNN e não anulado ou até exacerbado no meio } \\
\text { LIT. (YH) }\end{array}$ & $\begin{array}{l}\text { A ideia de "superação" é corroborada pelos } \\
\text { movimentos de "justificativa da limitação": "Esta } \\
\text { dificuldade pode estar... naturalmente infectadas" } \\
\text { e "sugerindo poder existir... ou até exacerbado no } \\
\text { meio LIT". A combinação da declaração dos } \\
\text { resultados com a corroboração da literatura } \\
\text { sugere que esta pesquisa deve ser continuada } \\
\text { neste sentido, para ser "purificada". O modal de } \\
\text { incerteza para a limitação da pesquisa ("esta } \\
\text { dificuldade pode estar"); o tempo verbal de } \\
\text { especulação (“que se refletiria também"), } \\
\text { projetando a ação no futuro; o conector } \\
\text { discursivo, "entretanto", para recuperar os dados, } \\
\text { são todos elementos linguísticos que contribuem } \\
\text { para direcionar a atenção da audiência à pesquisa. } \\
\text { A ordem dos movimentos - resultado inesperado, } \\
\text { justificativa, declaração de resultados, referência } \\
\text { à pesquisa prévia por corroboração, declaração de } \\
\text { resultados, dedução e hipótese - também } \\
\text { direciona a interpretação para a continuação da } \\
\text { pesquisa. }\end{array}$ \\
\hline
\end{tabular}

WALSH, Bianca. Ciência e linguagem: integrando discurso e contexto na análise das conclusões de artigos científicos experimentais do Memórias do Instituto Oswaldo Cruz (1909-1919 e 1980-1989). Linguagem em (Dis)curso - LemD, Tubarão, SC, v. 15, n. 1, p. 95-115, jan./abr. 2015. 
Para a interpretação dos argumentos, foram combinados os movimentos retóricos e as evidências linguísticas. Em alguns casos, a ordem dos movimentos retóricos foi determinante (veja exemplo de superação na Tabela 5).

Em suma, a análise do nível perlocucional resultou do intercruzamento das análises dos níveis locucional e ilocucional (veja Figura 1). A combinação dos três níveis da língua foi interpretada, por sua vez, considerando os dados do contexto em que os textos foram produzidos.

\section{RESULTADOS E DISCUSSÃO 3.1 CONTEXTO HISTÓRICO}

Algumas diferenças marcantes apareceram entre as comunidades discursivas de 1909-19 e de 1980-89 (Tabela 6). Quanto aos objetivos públicos, o primeiro período foi caracterizado pela produção de soros e vacinas e pela disseminação internacional da pesquisa local, enquanto o segundo período foi marcado basicamente pelo esforço de inserção em um contexto mais internacionalizado e estandardizado de pesquisa. No primeiro período, havia um espírito geral de pioneirismo, porque as pesquisas eram sobre doenças e espécies tipicamente brasileiras. O contexto era positivo porque o instituto teve sucesso em cumprir sua missão no Brasil e pôde ganhar reconhecimento internacional. A pesquisa brasileira era independente, no mesmo nível de igualdade daquele da ciência internacional.

A década de 80, por outro lado, foi marcada por um esforço constante de encontrar um lugar no cenário internacional da ciência. Nessa época, o mundo da ciência ganhou dimensões maiores (big science) e as interações entre cientistas eram mais complexas, para além dos interesses locais. A ciência e a tecnologia foram associadas com um tipo novo de economia e produção industrial. Para cientistas brasileiros, a pressão era ainda mais dramática porque não havia nenhum apoio governamental. A linguagem da ciência e o escrutínio dos pares haviam se padronizado e institucionalizado.

Quanto aos mecanismos de intercomunicação, ambos os períodos eram similares, porque os trabalhos eram publicados na maior parte em periódicos. Entretanto, no primeiro período, a maioria dos trabalhos eram publicados em periódicos nacionais, exatamente a situação contrária à do segundo período. Nos anos 80 , mesmo o MIOC estava se abrindo às submissões internacionais, e a maioria dos artigos eram escritos em inglês. Além disso, imagens, tabelas e gráficos ganharam importância como formas de intercomunicação neste período.

A respeito dos gêneros, entretanto, o primeiro período apresentou uma quantidade mais elevada de artigos descritivos de espécies. Nos anos 80, havia uma quantidade elevada de artigos científicos experimentais no formato IMRD, com as sessões delineadas no texto. Da mesma forma, apareciam as notas, que reproduzem a estrutura de artigos de pesquisa em um tamanho menor. Provavelmente, esse gênero era uma alternativa para o número crescente de artigos publicados e o espaço reduzido para publicar. 


\section{बDiscurso}

Tabela 6 - Caracterização das comunidades discursivas de 1909-19 e 1980-89

\begin{tabular}{|c|c|c|}
\hline Características & Período de 1909-19 & Período de 1980-89 \\
\hline Objetivos públicos & $\begin{array}{l}\text { Produção de soros, vacinas e medicamentos } \\
\text { para atender necessidades locais; pesquisa e } \\
\text { educação; e disseminação internacional da } \\
\text { pesquisa local (pioneirismo científico e } \\
\text { cenário positivo) }\end{array}$ & $\begin{array}{l}\text { Inserção no contexto internacional e } \\
\text { institucional da big science (competição e } \\
\text { cenário negativo) }\end{array}$ \\
\hline $\begin{array}{l}\text { Mecanismos de } \\
\text { intercomunicação }\end{array}$ & $\begin{array}{l}\text { Na maior parte, periódicos, mas também teses } \\
\text { de doutorado, artigos em tabloides populares e } \\
\text { apresentações em congressos e eventos. } \\
\text { Grande quantidade de publicação interna. }\end{array}$ & $\begin{array}{l}\text { Similar ao primeiro período. Todos os meios } \\
\text { eram mais internacionalizados e acessíveis. } \\
\text { Esforços em direção à publicação externa. } \\
\text { Imagens, gráficos e tabelas com maior } \\
\text { relevância. }\end{array}$ \\
\hline $\begin{array}{l}\text { Gêneros } \\
\text { compartilhados }\end{array}$ & $\begin{array}{l}\text { Artigos descritivos (de espécie) eram os mais } \\
\text { comuns. As sessões } \mathrm{IMRD}^{2} \text { não eram } \\
\text { delineadas no texto. }\end{array}$ & $\begin{array}{l}\text { O artigo de pesquisa prevalecia, com as } \\
\text { sessões IMRD delineadas claramente. Os } \\
\text { artigos descritivos eram ainda frequentes, } \\
\text { com as mesmas sessões IMRD (até 1987). } \\
\text { Emergência das notas, que, na prática, eram } \\
\text { artigos de pesquisa menores. }\end{array}$ \\
\hline $\begin{array}{l}\text { Posição } \\
\text { epistemológica } \\
\text { compartilhada }\end{array}$ & $\begin{array}{l}\text { - Ciência como progresso e civilização, } \\
\text { associada com patriotismo. } \\
\text { - Valorização do especialista. Atividade } \\
\text { científica como busca por excelência (vocação } \\
\text { mais elevada). } \\
\text { - Valores em construção: escrutínio dos pares } \\
\text { e linguagem como uma reprodução fiel da } \\
\text { realidade. } \\
\text { - Interação da pesquisa aplicada e básica para a } \\
\text { resolução de problemas práticos. } \\
\text { - O novo paradigma microbiológico. } \\
\text { - Movida a descoberta. Espírito Investigativo e } \\
\text { experimental. }\end{array}$ & $\begin{array}{l}\text { - Ciência como uma atividade globalizada, } \\
\text { conectada diretamente à economia e à } \\
\text { tecnologia. } \\
\text { - Investigador como um trabalhador e um } \\
\text { competidor incansáveis (grupo de pressão) } \\
\text { - Valores em consolidação: escrutínio dos } \\
\text { pares e linguagem padronizados e } \\
\text { institucionalizados. } \\
\text { - Superação da dicotomia pesquisa aplicada e } \\
\text { pesquisa básica a favor dos resultados. } \\
\text { - Interdisciplinaridade. } \\
\text { - Valorização da quantidade de trabalhos } \\
\text { publicados, do ineditismo e do modelo } \\
\text { experimental. }\end{array}$ \\
\hline
\end{tabular}

Em ambos os períodos, a ciência era valorizada como progresso. No primeiro período, no entanto, essa ideia de progresso era associada com o estabelecimento da civilização, a supressão de um atraso colonial e a expressão do patriotismo. O segundo período foi marcado pelo esforço para caber em um padrão novo de produção na ciência: uma ciência mais globalizada e vinculada à economia. Nesse período, a ciência seguia as leis do mercado: competição, busca por inovação e proeminência.

O cientista no primeiro período era considerado um herói. O "especialista" era valorizado por seu trabalho apaixonado e alcançava altos níveis de prestígio na comunidade internacional. O especialista era o oposto do "homem de retórica", símbolo da mentalidade colonial. Nos anos 80 , o cientista era uma pessoa agitada porque sua tarefa era hercúlea, considerando as restrições de orçamento e a competição para publicar.

No primeiro período, os valores da linguagem científica e do escrutínio dos pares estavam sendo estabelecidos. A linguagem era vista como uma fonte de interferência à ciência; deveria ser controlada para funcionar como um "espelho da realidade". O

\footnotetext{
${ }^{2}$ IMRD significa Introdução, Método, Resultados e Discussão. Trata-se da organização típica do artigo científico.
} 
escrutínio dos pares transformou-se na pedra de toque do trabalho em equipe e dos procedimentos de validação da ciência. Nos anos 80, aqueles valores já eram consolidados e alinhados com padrões institucionais.

A respeito da dicotomia ciência básica e ciência aplicada, ambos os momentos apresentaram integração. No primeiro momento, a integração foi favorecida pela urgência dos problemas (pestes humanas e do gado). Em 80, essa integração era motivada pela busca por resultados novos, que deveriam ser rentáveis. Havia também um movimento geral para a interdisciplinaridade.

Outra característica de ambos os períodos era o valor do ineditismo. No período de 1909-19, o ineditismo acontecia na mudança do paradigma "miasmático" para o novo paradigma microbiológico. O período foi marcado pelo pioneirismo e pela descoberta, em consequência da exploração do conhecimento. Em 80, o ineditismo concretizou-se na tentativa de adaptação a uma ciência internacionalizada, guiada pelo mercado, caracterizada pela competição. Ser novo significava ser inovador e proeminente.

\subsection{ASPECTOS LINGUÍSTICOS}

No período de 1909-1919, havia marcas linguísticas explicitamente subjetivas/pessoais, tais como a primeira pessoa (frequência relevante) e verbos que expressam volição e julgamento. Por outro lado, a tentativa de esconder o sujeito também pode ser notada (seguindo a lógica da linguagem científica objetiva) por meio da voz passiva (frequência relevante). Considerando os conectivos, os resultados mostram uma tendência para o tipo causa e efeito. Os achados não revelam complexidade e variedade em termos de adjetivos e advérbios, que expressam valores ou assertividade. Não havia nenhuma evidência de modalização ou atenuação, e nenhum traço de especulação. Uma tendência à projeção assertiva no futuro, denotando promessa/comprometimento, foi encontrada no uso do futuro. O seguinte exemplo ilustra a coexistência da subjetividade, na presença da primeira pessoa, e da simplicidade retórica.

\footnotetext{
Conclusões

Das nossas experiências, observações e pesquizas, podemos concluir resumidamente:

1o $\mathrm{O}$ anaplasma não é um protozoário.

2o O anaplasma é um corpusculo de natureza hamatica, produto de dejeneração dos globulos vermelhos.

3o O anaplasma é uma das dejenerações globulares decorrentes de certas anemias determinadas por venenos hemoliticos natureza diversa.

4o Não existe a moléstia denominada anaplasmose bovina que é, nos casos descritos por THEILER, uma forma clinica da piroplasmose. A anaplasmose dos outros mamíferos é devida a causas diversas (9A)
}

O período de 1980-89 foi caracterizado pela presença absoluta da voz passiva e pela presença frequente de verbos menos pessoais e mais objetivos com relação ao 
objeto do conhecimento. Esses achados revelam um alinhamento mais completo com a demanda para o objetividade na linguagem. Entretanto, junto com as evidências objetivas, há uma maior complexidade em termos da presença de advérbios e adjetivos, expressando veracidade, ênfase e preferência; mais traços de modalização, funcionando como atenuadores e apoiando a persuasão (especialmente através do verbo "dever" e recursos de ênfase); maior complexidade quanto ao uso de conectivos lógicos, expressando oposição, intensidade e ênfase; e mais especulação, por meio do futuro do pretérito. Todas essas evidências parecem juntas sugerir um texto científico mais dialógico em direção ao consenso.

\begin{abstract}
Discussão
A susceptibilidade experimental de B. amazonica e B. peregrina de diferentes regiões geográficas, aliada às modificações observadas em ralação à susceptibilidade de $\mathrm{B}$. straminea e B. tenagophila à infecção pelo S. mansoni em Minas Gerais, vem demonstrar a necessidade de mais pesquisas para uma melhor avaliação da potencialidade de outras espécies do mesmo gênero como hospedeiras deste trematódeo. Os planorbídeos B. straminea e B. tenagophila, considerados não transmissores em Minas Gerais, mas suscetíveis experimentalmente, estão sendo encontrados naturalmente infectados neste Estado. Dias Pinto et al.. (1984), relataram o encontro, em 1981, de B. straminea naturalmente infectada por S. mansoni na Represa Samambaia, localizada na divisa dos municípios de Lagoa Santa e Pedro Leopoldo, Minas Gerais. Melo, Pereira \& Corrêa (1982) registraram o primeiro encontro de B. tenagophila naturalmente infectada no município de Jaboticatubas, MG. Este foco continua ativo e Melo, Pereira \& Corrêa (1983) isolaram a cepa local de S. mansoni para estudos. Carvalho, Souza \& Katz (em publicação) registraram o primeiro encontro de B. tenagophila naturalmente infectada em Itajubá, Sul de Minas Gerais Carvalho et al. (comunicação pessoal) relataram o encontro deste mesmo planorbídeo naturalmente infectado por S. mansoni no lago da Pampulha, Belo Horizonte, MG.
\end{abstract}

Tais registros parecem indicar que os moluscos B.. straminea e B. tenagophila destas regiões estão se transformando em hospedeiros intermediários naturais do $\mathrm{S}$. mansoni, como ocorre no Nordeste brasileiro e em São Paulo.

No presente trabalho, tentou-se sem sucesso, a infecção experimental de B. schrammi com aquele trematódeo. Esta espécie de planorbídeo nunca foi encontrada naturalmente infectada ou se infectou experimentalmente com este parasita (Paraense, Fauran \& Courmes, 1964).

No decorrer do experimento, observou-se que este planorbídeo, de pequeno porte $(6-7 \mathrm{~mm}$ de diâmetro), tem grande tendência para fugir da água contendo miracídios, daí a utilização de placas de Petri com tampas para evitar sua saída da água durante a exposição aos miracídios. Também nos aquários de manutenção, durante o período pré-patente, observouse que 30 a $40 \%$ dos exemplares saíam da água e morriam dessecados nas paredes, tampas ou fora dos aquários, apesar de serem constantemente repostos dentro d'água. Este comportamento, provavelmente relacionado à pouca adaptação às condições de laboratório, foi o responsável pela taxa de mortalidade observada.

Assim, considerando-se as características inerentes a esta espécie, parece pouco provável que ela venha a ter alguma importância na epidemiologia da esquistossomose mansoni. Todavia, serão necessários mais experimentos com exemplares de outras populações de B. schrammi para uma avaliação mais segura do potencial deste planorbídeo como hospedeiro intermediário do S. mansoni. (6B).

Em suma, as evidências linguísticas do primeiro período sugerem subjetividade, mas o texto focaliza o objeto científico e mostra uma retórica simples. Nos anos 80 , há muitas evidências de objetividade, mas o texto mostra uma estrutura retórica complexa, através da qual o objeto do estudo é interconectado constantemente com a rede de pares. 
Dois cenários diferentes foram observados para os dois períodos, considerando a frequência total de movimentos retóricos. Considerando $70 \%$ como a frequência de corte, movimentos "virtualmente obrigatórios" (Peacock, 2002) foram identificados em ambos os períodos. Em 1909-1919, somente 'declaração de resultados' e 'dedução e hipótese' eram virtualmente obrigatórios. Inversamente, em 1980-89, 'referência à pesquisa prévia por corroboração' (presente em todo o corpus), 'delaração de resultados', 'dedução e hipótese', 'informação prévia', 'referência à pesquisa prévia por comparação' e 'implicação prática' eram virtualmente obrigatórios. Em 1909-19, 'retomada de método', 'implicação prática' e 'anúncio de limitação' eram movimentos opcionais (frequência de corte: 40\%). Em 1980-89, os movimentos opcionais eram 'explicação' e 'retomada de método'.

Assim, houve um aumento no uso de 'referência à pesquisa prévia por corroboração', 'informação prévia', 'referência à pesquisa prévia por corroboração' e 'implicação prática' em 80-89. Este perfil parece refletir uma rede complexa de interlocutores. Além disso, o valor da aplicação prática revela uma conexão da ciência às demandas objetivas do mundo externo. Em 1909-19, os movimentos retóricos refletem um foco nos achados e no método, que, devido ao cenário de ineditismo, estava provavelmente em consolidação.

A subdivisão do movimento de 'referência à pesquisa prévia' se mostrou importante, porque a 'corroboração' ultrapassou a 'comparação' nos anos 80. Este fato aponta para uma rede de pares mais positiva e próxima, sugerindo os valores de 'segurança' e 'validação', em oposição a uma rede antagonista e distante.

'Referência à pesquisa prévia', especialmente por corroboração, aparece na conclusão inteira, mas constitui especificamente padrões de começo e fim nas conclusões de 80. Consequentemente, também é importante considerar a distribuição dos movimentos. Um estudo que considere ciclos de movimento (PEACOCK, 2002) pode predizer a ordem e a ciclicidade, e ciclos de movimento são sensíveis a variações de disciplinas e de tempo.

Tirando proveito da proposta de Peacock (2002, p. 481), que dividiu as conclusões em três partes (introdução, avaliação e conclusão), os padrões de ciclo de movimentos no trabalho atual foram organizados na mesma maneira. Na introdução, os achados para o período 1909-1919 foram a presença de 'declaração de resultados' e 'dedução e hipótese', juntos ou separados. Em 80 o único padrão encontrado foi a presença do movimento 'referência à pesquisa prévia'.

Na avaliação, o período de 1909-19 apresentou somente o padrão 'declaração de resultados' + 'dedução e hipótese'. Nos anos 80 , os ciclos foram 'dedução e hipótese' + 'referência à pesquisa prévia por corroboração'; ' declaração de resultados' + 'referência à pesquisa prévia por corroboração'; 'declaração de resultados' + 'referência à pesquisa prévia por comparação'; e 'declaração de resultados' + 'dedução e hipótese'; 'Informação prévia' + 'referência à pesquisa prévia por corroboração' e 'referência à pesquisa prévia por comparação' + 'referência à pesquisa prévia por corroboração'. 
$\mathrm{Na}$ conclusão, o período de 1909-19 revelou um padrão diferente: 'Agradecimento' + 'justificativa de agradecimento'. Nos anos 80, os seguintes movimentos apareceram separadamente: 'Dedução e hipótese', 'implicação prática' e 'referência à pesquisa prévia por corroboração' (o último apareceu nas três partes das conclusões no período de 80).

Swales (1990) mostrou maior ciclicidade nas introduções das ciências humanas comparado às ciências exatas. $\mathrm{O}$ trabalho atual mostrou uma diferença diacrônica nas conclusões, porque o período de 1909-19 apresentou conclusões menos cíclicas quando comparadas com os textos em 80.

\subsection{ARGUMENTOS}

Em 1909-19, o argumento de 'desperdício' é o único "virtualmente obrigatório". Em 1980, o 'pragmático' e o 'desperdício' são virtualmente obrigatórios, sendo o primeiro mais frequente do que o último. $\mathrm{O}$ argumento do 'desperdício' repete a taxa de frequência encontrada no período de 1909-19.

Estes resultados revelam a interação da demonstração e da argumentação no discurso científico, ecoando a proposta de Rauch (1997) de que valores e crenças coexistem com o conhecimento científico racional. Favorecem também a ideia de que não há nenhum aspecto linguístico que possa sozinho determinar objetividade ou subjetividade. Particularmente, o estudo presente revela a presença da argumentação no discurso científico de duas formas: entrelaçamento e coexistência. Na primeira forma, a argumentação e a demonstração estão tão interconectadas que a distinção não pode ser percebida. A consequência é a "ilusão de objetividade". Na coexistência, ao contrário, a argumentação pode ser distinguida e projeta o trabalho científico por meio de sua promoção.

Em geral, os resultados revelam que em ambos os períodos a argumentação coexiste com a demonstração. Este fato é evidenciado pela presença do argumento do 'desperdício' em igual proporção em ambos os períodos. Este argumento promove o trabalho científico ao sugerir a ideia de que ele deve ser usado, continuado e aproveitado. Abaixo, há um exemplo deste argumento em cada período.

\footnotetext{
Aqui encerramos a expozição dos nossos rezultados sobre a vacinação contra a espiroquetoze, cujo emprego nos parece de todo o ponto recomendavel, como um dos meios mais praticos para se obter a profilaxia da dezimadora epizootia, tão comum entre nós. A mesma tecnica que usamos se recommenda, egualmente ao nosso ver, para o preparo de vacinas para as demais espiroquetozes como a Tick fever, a febre recurrente etc. (6A)

O presente trabalho, esclarecendo de modo mais detalhado a patologia da peste experimental em duas espécies de roedores potencialmente capazes de participar da eclosão de surtos epidêmicos em populações humanas, comprovou a possibilidade do desenvolvimento, nesses animais, de lesões hepáticas, esplênicas e pulmonares graves. Tais achados podem explicar, perfeitamente, a alta mortalidade observada em laboratório.
} 
É possível que, pelo menos parcialmente, alguns desses achados possam ser extrapolados para o homem, assegurando assim um melhor conhecimento da patologia provocada pela $Y$. pestis no organismo de outros hospedeiros susceptíveis. (3B)

Particularmente no período de 1980-1989, há o entrelaçamento da argumentação no discurso científico, manifestado pelo argumento 'pragmático', altamente frequente no período. Este argumento é entrelaçado com movimentos tipicamente demonstrativos e contribui para a construção das relações de causa e efeito envolvidas no trabalho experimental. No exemplo seguinte, o argumento 'pragmático' está entrelaçado na apresentação dos achados, favorecendo a causa "bloqueio ou exaustão do sistema imunológico do hospedeiro".

Outro achado histopatológico interessante diz respeito ao aspecto da polpa branca no baço dos animais infectados, notando-se acentuada atrofia dos folículos de Malpighi, com ausência de centros reacionais, sugerindo um possível bloqueio ou exaustão do sistema imunológico do hospedeiro, face à intensa agressão antigênica provocada pela liberação maciça de endotoxina bacteriana. (3B)

Esta ocorrência revela uma manifestação argumentativa mais complexa nos anos 80: interna e sutil ou externa e evidente.

\subsection{SÍNTESE DOS RESULTADOS EM DIREÇÃO A UM MODELO INTEGRADO}

Nesta seção, as análises integradas das conclusões de ambos os períodos são apresentadas, e um modelo geral, abstraindo-se as peculiaridades diacrônicas, é proposto.

A análise de 1909-1919 (Tabela 7) sugere um foco nos achados científicos. Esse aspecto é corroborado pela simplicidade da sequência lógica textual e pela ausência de uma complexidade persuasiva. Os movimentos retóricos predominantes também corroboram este foco, já que os resultados são recuperados (declaração de resultados) e transformam-se no eixo do raciocínio do investigador (dedução e hipótese).

Tabela 7 - Análise das Conclusões (1909-1919)

\begin{tabular}{l|l}
\hline Níveis da Análise & $\mathbf{1 9 0 9 - 1 9 1 9}$ \\
\hline Locucional & $\begin{array}{l}\text { Marcas de subjetividade explícita: primeira pessoa e verbos de julgamento e volição; voz } \\
\text { passiva; conectivos de causa e efeito; projeção futura assertiva (futuro do presente) }\end{array}$ \\
\hline Ilocucional & $\begin{array}{l}\text { Movimentos Obrigatórios: Dedução e hipótese e declaração de resultados. Movimentos } \\
\text { opcionais: Retomada do método, implicação prática, anúncio de limitação. Arranjo linear. } \\
\text { Padrões: Declaração de resultados + dedução e hipótese (começo e meio das conclusões); }\end{array}$ \\
\hline Agradecimento + justificativa para agradecimento (fim das conclusões).
\end{tabular}


Além disso, o período sugere a promoção/projeção dos achados, sustentados pelo argumento do 'desperdício'. Essa projeção é corroborada pela tendência de se usar o futuro e os movimentos de 'implicação prática', 'anúncio de limitação' (já que acarreta na superação da limitação) e 'retomada de método' (que contribui para a continuação da pesquisa).

A conclusão de 1980-89 parece focalizar na rede de pares; os achados científicos são construídos na interação com esta rede (como eixo) e projetados/promovidos para a mesma rede. Essa complexidade discursiva é reforçada por elementos linguísticos e retóricos. As características linguísticas revelam marcas de diálogo e busca por consenso: modais; conectivos que denotam contraste, intensidade e ênfase; uso de futuro do pretérito representando especulação e, busca por consenso; e adjetivos e advérbios que denotam veracidade, ênfase e preferência (valores que reforçam também a busca por consenso). Por outro lado, os movimentos retóricos 'referência à pesquisa prévia por corroboração', 'referência à pesquisa prévia por comparação' e 'informação prévia' (recuperando o conhecimento tácito compartilhado pela rede de pares) são todos evidências para a participação da rede de pares na construção das conclusões.

Tabela 8 - Análise das Conclusões (1909-1919)

\begin{tabular}{l|l}
\hline Níveis da Análise & $\mathbf{1 9 8 0 - 1 9 8 9}$ \\
\hline Locucional & $\begin{array}{l}\text { Marcas de objetividade: voz passiva e verbos objetivos. Complexidade de adjetivos e advérbios } \\
\text { (noções de veracidade, enfase e preferência). Modalização. Complexidade de conectivos lógicos } \\
\text { (contraste, intensidade e ênfase). Especulação (futuro do pretérito) }\end{array}$ \\
\hline Ilocucional & $\begin{array}{l}\text { Movimentos Obrigatórios: Dedução e hipótese, declaração de resultados, referência à pesquisa } \\
\text { prévia por corroboração, referência à pesquisa prévia por comparação, implicação prática e } \\
\text { informação prévia. Movimentos opcionais: Retomada de método explicação. Arranjo cíclico. } \\
\text { Padrões: Referência à pesquisa prévia por corroboração (começo das conclusões); declaração de } \\
\text { resultados + dedução e hipótese, declaração de resultados + referência à pesquisa prévia por } \\
\text { corroboração, declaração de resultados + referência à pesquisa prévia por comparação, } \\
\text { informação prévia + referência à pesquisa prévia por corroboração, referência à pesquisa prévia } \\
\text { por corroboração + referência à pesquisa prévia por comparação, dedução e hipótese + referência } \\
\text { à pesquisa prévia por corroboração (meio das conclusões); referência à pesquisa prévia por } \\
\text { corroboração, dedução e hipótese, e implicação prática (fim das conclusões). }\end{array}$ \\
\hline Perlocucional & $\begin{array}{l}\text { Argumento pragmático (entrelaçamento da argumentação e da demonstração). Argumento do } \\
\text { desperdício (coexistência da argumentação e da demonstração). }\end{array}$ \\
\hline Síntese & $\begin{array}{l}\text { Foco na rede de pares, o resultado do trabalho científico é construído no processo de interação } \\
\text { com a rede, para ser promovido/disseminado, então, para a mesma rede. }\end{array}$ \\
\hline
\end{tabular}

O argumento 'pragmático' revela a construção intricada das conclusões, uma vez que os achados científicos e as considerações sobre eles estão entrelaçadas na imbricação da argumentação e da demonstração. Em contraste, a ideia de promoção é expressa pelo argumento de 'desperdício', que induz a continuação do trabalho científico. O movimento de 'implicação prática' mais os elementos linguísticos (adjetivos, advérbios e recursos de ênfase) corroboram a ideia da continuação.

Comparando os dois modelos de conclusão, o resultado é a seguinte reapresentação visual (Figura 2). Para representar o fato de que a pesquisa é um objeto projetado/promovido para a comunidade de discurso (1909-19), as setas estão apontadas unilateralmente para a comunidade. 
Figura 2 - Representação gráfica dos modelos de conclusão dos dois períodos estudados

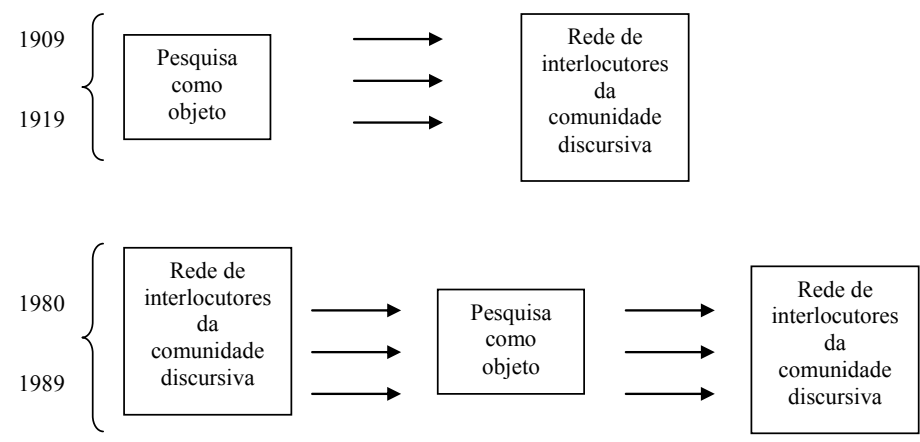

Figura 2: Representação gráfica dos modelos de conclusão dos dois períodos estudados

Inversamente, o período de 1980-89 é caracterizado por uma maior complexidade na interação da comunidade com a pesquisa como um objeto. A rede de pares participa na construção das conclusões, entrelaçada no texto, que é, por sua vez, promovido a esta mesma comunidade. A representação (Figura 2) mostra este retorno pelo fato de que a rede de pares está nas duas posições extremas do esquema.

De um outro ponto de vista, o modelo das conclusões pode ser projetado abstraindo-se as peculiaridades de cada período (Figura 3). A representação gráfica mostra o modelo integrando os três níveis do discurso na interação com os fatores contextuais.

\section{Figura 3 - Modelo de conclusão por abstração dos traços diacrônicos}
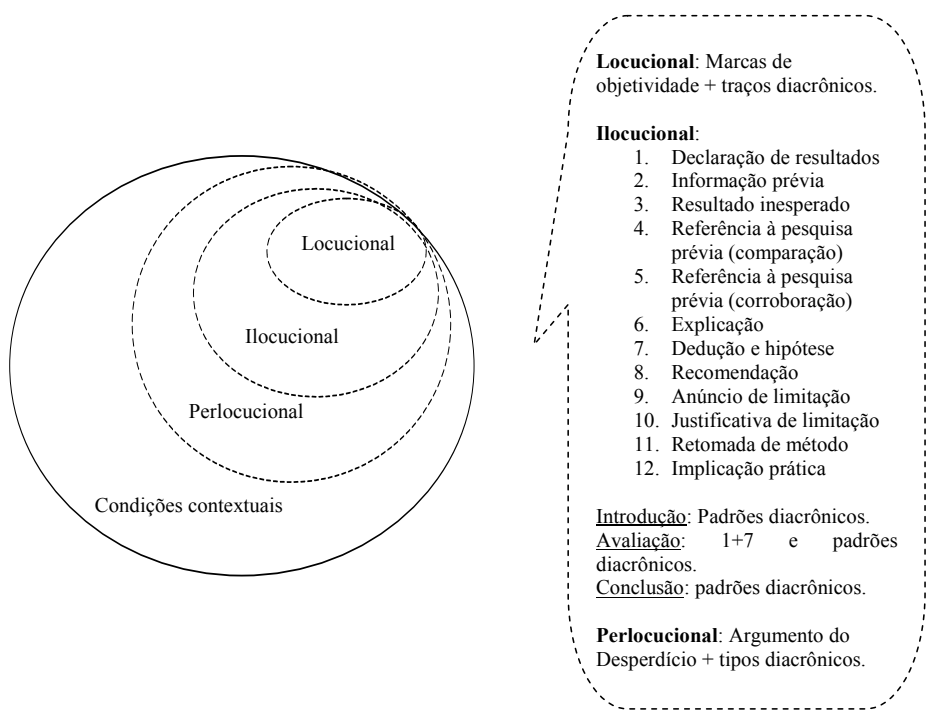

No nível locucional, somente as marcas de objetividade, tal como a voz passiva, foram encontradas, sugerindo que o projeto de uma língua científica objetiva tinha iniciado já no começo do século 20. No nível ilocucional, uma lista de movimentos mais frequentes e padrões de movimentos foi elaborada, considerando o modelo 
tripartido proposto por Peacock (2002, p. 481), que parece flexível o bastante para as finalidades do presente artigo. Os movimentos que se mostraram diacrônicos não foram considerados na lista. Somente um padrão foi constante em ambos os períodos, e somente na avaliação da conclusão: Dedução e hipótese + declaração de resultados. Finalmente, no nível perlocucional, o argumento do 'desperdício' aparece tipicamente.

Em termos de circunstâncias contextuais, a comunidade de 1909-19 era pequena, homogênea, patriota e pioneira. Esses aspectos correlacionam-se com as marcas de pessoalização, o texto linear e a baixa complexidade retórica. A argumentação sugere a promoção das pesquisas no mesmo nível de prestígio de pesquisas internacionais. No período de 1980-89, a comunidade era grande e caracterizada como "um grupo pressão", que se esforçava para caber nos padrões da ciência internacional (big science). Esses aspectos estão correlacionados com uma maior força retórica e uma complexa imbricação entre a pesquisa e a rede de pares. Apesar de mais objetivas, pelo controle de determinadas marcas linguísticas de pessoalização, as conclusões neste período eram artefatos retóricos/argumentativos verdadeiramente elaborados.

\section{CONCLUSÕES}

Este trabalho analisou as conclusões de artigos científicos experimentais de dois períodos: 1909-19 e 1980-89. No primeiro período, as conclusões eram lineares e relativamente simples em termos retóricos, com um foco nos achados de pesquisa a serem promovidos para a comunidade dos pares. Esses dados correlacionam-se com uma comunidade pequena e coesa, que favorecia o consenso. Esta comunidade estava no mesmo nível de cientistas internacionais, gozando de prestígio como pioneiros em pestes e espécies tropicais. Uma outra característica era a adoção gradual do escrutínio dos pares e da linguagem científica padronizados.

No período de 1980-89, as conclusões eram cíclicas e retoricamente complexas. Uma peculiaridade foi a ocorrência do argumento 'pragmático'. Essas características são correlacionadas com uma atmosfera de pressão, em que a comunidade dessa época não contava com nenhum apoio do governo e se esforçava para se adaptar às dimensões da big science. A superfície dos textos vincula objetividade e pura demonstração. Entretanto, uma análise completa, considerando os três níveis da língua em contraste com o contexto, mostra o oposto.

O trabalho contribui com os estudos do gênero ao propor um modelo de conclusões que vá além da descrição tradicional de movimentos retóricos e de aspectos linguísticos somente, integrando estes níveis de língua com o nível perlocucional em contraste com os fatores contextuais.

Outra contribuição do artigo é para os estudos da ciência, já que a ideia de que a ciência é sensível a valores diacrônicos e de que envolve persuasão foi demonstrada. Especificamente a respeito da ciência brasileira, o artigo recupera o momento de prestígio e brilhantismo experimentado por cientistas do começo do século 20 e revela um cenário de esforço para adaptar-se a um novo momento da ciência, sem nenhum apoio governamental, nos anos 80 . 
Em termos pedagógicos, o trabalho corrobora a ideia de que o treinamento acadêmico deve considerar, além do conhecimento de textos acadêmicos, uma perspectiva crítica sobre gêneros e comunidades do discurso. Particularmente, os aprendizes devem ser investigadores de suas próprias comunidades científicas para perceber seus valores e crenças e para observar como esses elementos influenciam os textos. Devem também compreender que não há nenhum critério absoluto para definir ciência como boa ou ruim e que a linguagem/discurso é uma evidência de que a persuasão é parte da prática científica. A abordagem pedagógica para fins acadêmicos deve ser, portanto, necessariamente crítica e incluir os aprendizes na pesquisa de gêneros e comunidades, com o objetivo de fazer descobertas mais reais sobre hábitos e valores disciplinares.

\section{REFERÊNCIAS}

ATKINSON, D. Scientific discourse in sociohistorical context: The Philosophical Transactions of the Royal Society of London, 1675-1975. Lawrence Erlbaum Associates, 1999.

AYERS, G. The evolutionary nature of genre: An investigation of the short texts accompanying research articles in the scientific journal Nature. English for Specific Purposes, v. 27, p. 22-41, 2008.

BRUCE, I. Cognitive genre structures in Methods sections of research articles: A corpus study. Journal of English for Academic Purposes, v. 7, p. 38-54, 2008.

CORACINI, M. J. Um fazer persuasivo: o discurso subjetivo da ciência. São Paulo: Pontes Educ, 1991.

GUIMARÃES, E. Expressão modalizadora no discurso de divulgação científica. Educação e Linguagem, v. 4, n. 5, p. 65-77, 2001.

JOHNS, A. M. et al. Crossing the boundaries of genre studies: commentaries by experts. Journal of Second Language Writing, v. 15, p. 234-49, 2006.

KANOKSILAPATHAM, B. Rhetorical Structure of Biochemistry Research Articles. English for Specific Purposes, v. 24, p. 269-292, 2005.

KOCH, I.G.V. Argumentação e linguagem. São Paulo: Cortez, 2006.

MORAES, L. S. B. O metadiscurso em artigos acadêmicos: variação intercultural, interdisciplinar e retórica. 2005. 194 f.. Tese (Doutorado em Letras) - Faculdade de Letras, Pontifícia Universidade Católica do Rio de Janeiro, Rio de Janeiro, 2005.

NEVES, M. H. M. Texto e gramática. São Paulo: Contexto, 2007.

NWOGU, K.N. The medical research paper: structure and functions. English for Specific Purposes, v. 16, n. 2, p. 119-38, 1997.

PEACOCK, M. Communicative moves in the discussion section of research articles. System, v. 30, p. 479-497, 2002.

PERELMAN, C.; OLBRECHTS-TYTECA, L. Tratado da argumentação: A Nova Retórica. São Paulo: Martins Fontes, 2005.

RAMANATHAN, V.; KAPLAN, R. B. Genres, authors, discourse communities: theory and application for (L1 and) L2 writing instructors. Journal of Second Language Writing, v. 9, n. 2, p. 171-191, 2000.

RAUCH, Y. M. The rhetoric of the probable in scientific commentaries: The debate over the species status of the red wolf. Technical Communication Quarterly, v. 6, n. 1, p. 91-104, 1997.

SALAGER-MEYER, F. Referential Behavior in Scientific Writing: a Diachronic Study (1810 \pm 1995$)$. English for Specific Purposes, v. 18, n. 3, p. 279-305, 1999.

SAMRAJ, B. Introductions in research articles: variations across disciplines. English for Specific Purposes, v. 21, p. 1-17, 2002.

SCHWARTZMAN, S. Pesquisa científica no Brasil: Matrizes culturais e institucionais. Em

GONÇALVES. E. L. G. (Ed.). Pesquisa médica. São Paulo: Editora Pedagógica Universitária, 1982. p. 137-160. 
A capacidade institucional da pesquisa no Brasil. Texto preparado para o Seminário "Desarrollo de la Capacidad Institucional para la investigación en América Latina y el Caribe", Bogotá, Colômbia, December 4 to 7, 1991.

Catching up in science and technology: self-reliance or internationalization? Artigo preparado para o Seminário "Nationalism and Internationalism of Science", Congresso Mundial da Associação Sociológica Internacional, Beielefeld, Germany, July 18-23, 1994.

SWALES, J. M. Genre Analysis: English in academic and research settings. New York: Cambridge University Press, 1990.

Research genres: explorations and applications. New York: Cambridge University Press, 2004.

UPTON, T.A.; CONNOR, U. Using computurized corpus analysis to investigate the text linguistic discourse moves of a genre. English for Specific Purposes, v. 20, p. 313-329, 2001.

VAN DIJK, T. A. Pragmatic macro-structures in discourse and cognition In: MEY, M. de et al., (Eds.) CC 77, p. 99-113, 1977. University of Ghent. Disponível em:

$<$ http://www.discourses.org/download/articles/> Acesso em: 03 jul. 2014.

\section{Recebido em: 03/07/14. Aprovado em: 12/02/15.}

Title: Science and language: integrating discourse and context in the analysis of the Conclusions of experimental scientific articles of The Oswaldo Cruz Institute Memories (1909-1919 and 1980-1989)

Author: Bianca Walsh

Abstract: The Conclusions of the experimental scientific articles from a traditional Brazilian journal were analyzed considering the 1909-19 and 1980-89 periods. The analysis integrated language and context by revealing types of arguments, rhetorical moves and linguistic traits. The findings were the change from a linear and less rhetorically elaborated discourse in the first period to a highly rhetorical density and cyclicity in the second period. They were correlated with the change from a cohesive, small and prestigious community into a big community, pressured to adapt to the parameters of the big science, with no governmental support. The contributions to the genre analysis, studies of science and teaching for academic purposes are discussed.

Keywords: Science and language. Experimental scientific article. Conclusion section. Genre studies.

Título: Ciencia y lenguaje: integrando discurso y contexto en el análisis de las conclusiones de artículos científicos experimentales del Memórias do Instituto Oswaldo Cruz (1909-1919 e 1980-1989)

Autor: Bianca Walsh

Resumen: En este trabajo fueron analizadas las conclusiones de los artículos cientificos experimentales de una revista científica brasileña tradicional, considerando los períodos de 1909-19 y 1980-89. El análisis integró lengua y contexto al revelar tipos de argumentos, movimientos retóricos y trazos lingüísticos. Los resultados apuntan el cambio de un discurso lineal y menos retóricamente elaborado en el primero período para una densidad y característica cíclica altamente retóricas en el segundo. Eses resultados se correlacionan con el cambio de una comunidad prestigiosa, cohesiva y pequeña para una comunidad populosa y presionada a adaptarse con los parámetros de la big science, sin ningún apoyo del gobierno. Son discutidas contribuciones a los estudios de género, estudios de la ciencia y enseñanza para fines académicos.

Palabras-clave: Ciencia y lenguaje. Artículo científico experimental. Sección de conclusión. Estudios de géneros. 